\title{
СОЦИАЛЬНО-ГУМАНИТАРНЫЕ НАУКИ
}

DOI: $10.24143 / 1812-9498-2019-1-57-62$

УДК 811:161:1

\section{ИСПОЛЬЗОВАНИЕ МЕТОДА ТЕSТ-ТЕАСН-ТЕSТ НА ЗАНЯТИЯХ ПО АНГЛИЙСКОМУ ЯЗЫКУ}

\author{
Е. В. Артемьева, В. С. Голубева \\ Государственный университет морского и речного флота \\ имени адмирала С. О. Макарова, \\ Санкт-Петербург, Российская Федерация
}

\begin{abstract}
Рассмотрены преимущества тестирования как метода проверки знаний в процессе преподавания английского языка, его виды и особенности. Одним из результативных методов предварительного тестирования является метод Test-Teach-Test. Применение Test-Teach-Test проводилось на протяжении семестра среди студентов первых и вторых курсов обучения по специальности «Технология транспортных процессов» Государственного университета морского и речного флота имени адмирала С. О. Макарова. По результатам исследования было выявлено, что экспериментальные группы, в которых применялся метод Test-Teach-Test, демонстрировали лучшее усвоение материала по сравнению с теми группами студентов, в обучении которых данный метод не применялся. Очевидно, что его использование позволяет оптимизировать процесс преподавания английского языка, рационально распределить время в ходе обучения, применять индивидуальный подход к студентам и уделять максимальное внимание слабо изученному материалу.
\end{abstract}

Ключевые слова: иностранный язык, тестирование, процесс обучения, уровень знаний, Test-Teach-Test, успеваемость, контроль знаний.

Для цитирования: Артемьева E. В., Голубева В. C. Использование метода Test-Teach-Test на занятиях по английскому языку // Вестник Астраханского государственного технического университета. 2019. № 1(67). С. 57-62. DOI: 10.24143/1812-9498-2019-1-57-62.

\section{Введение}

Процесс преподавания предполагает обязательное взаимодействие между педагогом и учащимися в рамках определенной дисциплины и активное участие в нем обеих сторон. В этом контексте преподавание является совместной работой студентов и преподавателей, где преподаватель несет ответственность за успехи обучающихся. Преподаватель при этом не только делится знаниями, но и проверяет эффективность и результативность своей работы, а также навыки, приобретаемые учащимися. То есть обучение и проверка знаний неотделимы друг от друга, и тестирование в качестве проверки знаний является неотъемлемой частью учебного процесса.

Тестирование как процесс измерения способностей и знаний учащихся в определенной области посредством проверки этих знаний предназначено, в частности, для того, чтобы мотивировать учащихся повысить свою успеваемость. В этом контексте профессор прикладной лингвистики Пит Кордер отмечает, что языковые тесты являются измерительными инструментами и применяются в первую очередь к учащимся, а не к учебным материалам или преподавателям. Он поясняет, что результаты тестов не говорят напрямую о вкладе преподавателя или используемых им материалов в учебный процесс, а предназначены, прежде всего, для измерения знаний учащихся и их языковых компетенций на определенном этапе обучения [1]. Знания одного обучающегося можно сравнить со знаниями других студентов или со знаниями того же обучающегося в другое время. 
Под языковым тестированием понимается измерение способностей и знаний студентов, изучающих определенный аспект иностранного языка. Всемирно известный методист Пенни Ур [2] приводит следующие преимущества тестирования как метода проверки знаний:

-преподаватель получает информацию о том, на каком уровне находятся студенты в данный момент, затем принимает решение о задачах на перспективу: следует ли продолжать преподавание без внесения изменений в процесс или пересмотреть (изменить) свои методики обучения;

- студенты также получают информацию о том, что и в каком объеме они усвоили, нужно ли им идти вперед или следует повторить пройденный материал;

-по результатам тестирования можно отнести учащегося к той или иной подгруппе (например, к продолжающей или начинающей) для дальнейшего освоения языка;

- преподаватель узнает, насколько успешны его методы.

Тестирование используется для получения информации об особенностях работы преподавателя и восприятия студентов, касающихся различных аспектов процесса обучения иностранному языку. Оно помогает заинтересованным сторонам судить о том, насколько эффективен процесс обучения, и на основе информации, полученной в результате тестирования, могут быть предприняты некоторые шаги для совершенствования процесса обучения.

Следует также отметить, что тестирование является формой организации самостоятельной работы студентов [3].

\section{История развития тестирования в преподавании иностранного языка}

Рассмотрим тестирование и его историческую эволюцию в рамках преподавания английского языка более подробно, основываясь на материале, почерпнутом из иностранных источников.

Языковое тестирование сыграло значительную роль в развитии образовательной среды.

Характер преподавания английского языка и проверки знаний претерпел изменения в ходе исторического процесса. Признанный специалист по методике преподавания английского языка Д. Ричардс [4] резюмирует относительное доминирование следующих методов обучения иностранному языку в разные периоды последних двух столетий:

- грамматико-переводной метод (1800-1900 гг.);

- прямой метод (1890-1930 гг.);

- структурный метод (1930-1960 гг.);

- метод чтения (1920-1950 гг.);

- аудиоречевой метод (1950-1970 гг.);

- коммуникативный подход (1970 г. - настоящее время).

Грамматико-переводной метод преобладал в обучении английскому языку вплоть до начала XX в. Согласно исследованию, проведенному Л. Джин и М. Кортацци [5], данный метод предполагал, что двуязычные словарные списки и упражнения по переводу наряду с чтением литературных текстов способствуют оптимальному усвоению грамматических правил. Таким образом, обучение английскому языку сводилось к освоению навыков перевода, грамматических правил и чтению литературного текста. После критики грамматико-переводного метода получил широкое признание и был внедрен в преподавание и изучение английского языка прямой метод. Он поощрял использование изучаемого языка в качестве средства обучения, а грамматика преподавалась индуктивно. Этот метод также включал в себя проверку устных коммуникативных навыков. Американский лингвист Д. Ларсен-Фриман [6] признает, что в середине XX в. доминировал аудиоречевой метод, основанный на преподавании английского языка как средства устного общения. Метод предполагал и преподавание грамматики с помощью шаблонных упражнений и диалогов. Проверялось, в первую очередь, восприятие речи на слух и ее устное воспроизведение. Позднее различные теоретические и философские течения способствовали возникновению коммуникативного подхода к преподаванию английского языка. Ричардс отмечает, что преподавание коммуникации на английском языке предполагает широкий подход к обучению, в центре которого стоит общение в целом, а не только грамматический строй языка [4]. Начало развития коммуникативного подхода датируется 1970-ми гг., и именно к этому периоду относится возникновение понятия «коммуникативной компетенции», впервые примененного лингвистом Деллом Хаймсом [7] по отношению к процессу преподавания. Именно коммуникативный подход послужил основой для возникновения таких способов преподавания английского языка, как совместное участие (participatory approach), обучение путем решения 
поставленной задачи (task based learning) и др. В рамках коммуникативного подхода стало интенсивно развиваться тестирование как часть преподавания английского языка в современном понимании этого слова.

Тестирование как проверка знаний информирует преподавателя о том, чего обучающийся достиг в процессе обучения и демонстрирует, как и насколько его результаты отличаются от результатов других студентов, что, в свою очередь, позволяет выработать некий индивидуальный подход к каждому из них. В то же время полученные результаты косвенно предоставляют информацию о самом процессе обучения, об эффективности использования тех или иных методов. В этом смысле тесты дают возможность судить не только об успеваемости студентов, но и о результативности работы преподавателей. Результаты теста отражают то, насколько хорошо преподаватель преподнес материал и насколько хорошо учащиеся его усвоили.

\section{Виды тестирования для оценки знаний}

В современном преподавании в качестве проверки знаний используются различные типы тестовых заданий. Тестирование является важной частью в системе методов контроля и оценки знаний студентов [8]. Языковые тесты являются основным инструментом, используемым для оценки качества обучения в большинстве учебных заведений. И хотя может показаться, что все тесты приблизительно одинаковы, существует много разных типов тестов, каждый из которых имеет свое назначение и особенности.

Диагностические тесты (diagnostic test) используются для диагностики того, что именно и в каком объеме знают студенты. Такие тесты могут помочь преподавателю понять, что нужно проверить или закрепить на занятиях в аудитории. Они также позволяют студентам выявить слабые места в усвоенных знаниях.

Тесты для определения языкового уровня (placement test) используются для определения уровня владения языком и дальнейшего распределения по группам. В частности, в таких тестах проверяются знание грамматики, наличие определенного словарного запаса, способность понимания прочитанного, навыки письма и разговорной речи.

Тесты прогресса или достижений (progress and achievement test), или тесты успеваемости, являются средством мониторинга успешности подготовки студентов. В этих тестах проверяется только тот материал, который студенты изучали на занятиях. Существует два типа тестов прогресса и достижений: краткосрочные и долгосрочные.

Краткосрочные тесты успеваемости позволяют проверить, насколько хорошо студенты поняли и усвоили материал, изложенный в отдельных разделах или главах. Они позволяют преподавателю решить, чему следует уделить особое внимание: исправлению типичных ошибок или закреплению пройденного материала.

Долгосрочные тесты прогресса также называются курсовыми тестами, потому что они проверяют успеваемость, достигнутую по окончании всего курса обучения. Они позволяют студентам судить, насколько они продвинулись в изучении того или иного предмета. В зарубежных учебных заведениях зачастую по результатам именно этих тестов учащиеся могут перейти на более высокий уровень обучения (на другой курс).

Международные стандартизованные тесты для профессиональных целей (proficiency tests) позволяют проверить уровень знаний студентов на предмет соответствия общим стандартам, давая широкую картину их знаний и способностей. При изучении английского языка примерами таких тестирований-экзаменов являются, в частности, TOEFL (Test of English as a Foreign Language) и IELTS (International English Language Testing System), которые обязательны для желающих поступить в англоязычные университеты. Также можно упомянуть экзамен TOEIC (Test of English for International Communication), который диагностирует навыки делового общения на английском языке и применяется иностранными компаниями при трудоустройстве.

При проведении тестирования на занятиях по английскому языку среди студентов (курсантов), обучающихся по специальности 23.03.01 «Технология транспортных процессов», преподавателями используются различные виды тестов, благодаря чему достигается большая достоверность результатов. Например, перед началом обучения все поступившие с помощью теста для определения уровня владения английским языком (placement test) распределяются на две подгруппы в зависимости от уровня языковой подготовки: начинающую и продолжающую.

Диагностические тесты (diagnostic test) используются преподавателями на протяжении семестра при введении нового лексического и грамматического материала. 


\section{Преимущества использования метода Test-Tech-Test}

Итак, тестирование как проверка знаний является частью учебного процесса. Существует целая система оценки знаний и рейтингового тестирования студентов [9].Тестирование не может быть отделено от обучения, и наоборот. Задача преподавателя в процессе обучения состоит не только в том, чтобы преподнести материал, но и проверить, насколько хорошо учащиеся освоили то, чему их учили, и насколько эффективны материалы и методы, которые использует преподаватель. Так, в ГУМРФ им. адм. С. О. Макарова уже на протяжении многих лет проводится тестирование студентов первых курсов в начале учебного года с целью выявления их знаний, касающихся грамматики английского языка. А с 2018 г. проводится и комплексное тестирование, охватывающее не только грамматический аспект, но и понимание прочитанного, и восприятие английской речи на слух. Такой комплексный подход значительно облегчает и улучшает дальнейшую работу преподавателя, выявляя изначальные знания студентов максимально объемно.

Таким образом, перед преподавателями английского языка стояла задача оптимизации учебного процесса и рационального использования времени занятий без изменения при этом рабочих программ кардинальным образом. Особенно это было актуально для преподавателей английского языка, работающих в Государственном университете морского и речного флота имени адмирала С. О. Макарова (ГУМРФ им. адм. С. О. Макарова) на факультете международного транспортного менеджмента. Ведь дисциплины, преподаваемые на факультете и связанные с английским языком («Английский язык», «Базовый профессиональный английский язык», «Деловой английский язык»), изучаются здесь на протяжении всех 4-х лет обучения, обучение заканчивается сдачей государственного экзамена государственной аттестационной комиссии, что мотивирует студентов и преподавателей максимально серьезно отнестись к поставленной задаче и искать пути ее решения. В связи с вышесказанным было принято решение обратиться к методу Test-Teach-Test - методу предварительного тестирования на знание конкретных языковых аспектов - и использовать его на протяжении процесса обучения.

Метод Test-Teach-Test - это один из способов проверить текущий уровень знаний учащихся, выявить проблемы и предпринять соответствующие действия, способствующие лучшему освоению материала. Метод Test-Teach-Test - это своего рода способ организации занятия по иностранному языку, хотя он может быть успешно применим и на занятиях по целому ряду других дисциплин. Этот метод обучения предполагает, что учащиеся, прежде чем подробно изучить новый языковой материал, сначала выполняют задание без какой-либо поддержки со стороны преподавателя и проходят так называемое предварительное тестирование. Учитель проводит предварительный тест по конкретной теме и уже после этого, основываясь на результатах теста, планирует занятия по введению нового языкового материала. Такой способ позволяет рационально использовать время занятий, сконцентрироваться на наиболее значимых аспектах и, при необходимости, использовать индивидуальный подход при подаче материала. Особенно это актуально в группах разного уровня языковой подготовки, в которых обучаются студенты, уже имеющие неплохую базу, полученную в рамках средней школы. Таким образом, после предварительного тестирования студенты участвуют в процессе, направленном на освоение новых знаний, а в завершение преподаватель еще раз проверяет успеваемость учащихся, а те, в свою очередь, выполняют еще одну задачу для отработки нового языкового материала.

Метод Test-Teach-Test был успешно апробирован и сейчас активно применяется на занятиях по английскому языку при обучении студентов ГУМРФ имени адмирала С. О. Макарова по специальности «Технология транспортных процессов». На основе анализа и интерпретации данных, полученных в результате проведенного тестирования, была получена информация о качестве проделанной работы, об эффективности различных методов обучения, о работе группы обучаемых в целом и каждого студента в отдельности. Это значительно облегчило работу преподавателей кафедры по сравнению с предыдущим периодом, когда данный тип тестирования не использовался. Успеваемость выросла в среднем на 15 \%, что является неплохим показателем среди студентов указанной специальности. В дальнейшем эти данные могут служить основанием для индивидуализации и дифференциации обучения, а также правильного планирования процесса обучения и более целенаправленного распределения учебного времени. 


\title{
Заключение
}

Тестовые технологии становятся наиболее перспективной формой контроля знаний. Как показывает опыт, тестирование позволяет объективно и оперативно проверить уровень знаний студентов, а также своевременно ликвидировать пробелы в усвоении лексического и грамматического материала. Применение метода Test-Teach-Test помогает рационально выстроить программу обучения и добиться более высоких результатов при обучении студентов разного уровня языковой подготовки.

\section{СПИСОК ЛИТЕРАТУРЫ}

1. Corder S. P. Introducing applied linguistics. Harmondsworth; Baltimore: Penguin Books, 1973. 392 p.

2. Ur P. A course in language teaching. Cambridge: Cambridge University Press, 2012. 336 p.

3. Груздева М. Л., Козицын А. Л. Тестирование как форма организации самостоятельной работы студентов // Современные наукоемкие технологии. 2016. № 7-1. С. 118-121.

4. Richards J. C. Curriculum development in language teaching. Cambridge: Cambridge University Press, $2001.336 \mathrm{p}$.

5. Jin L., Cortazzi M. Re-evaluating traditional approaches to second language teaching and learning // Handbook of research in second language teaching and learning. 2011. V. 2. P. 558-575.

6. Larsen-Freeman D. Techniques and principles in language teaching. Oxford: Oxford University Press, 2000. $208 \mathrm{p}$.

7. Hymes D. On communicative competence // Sociolinguistics. Selected Readings. J. B. Pride and J. Holmes (eds.). Harmondsworth: Penguin, 1972. Part 1. P. 269-293.

8. Тимофеев Д. А., Печникова А. Д., Абызова Н. В. Тестирование в системе методов контроля и оценки знаний студентов // Междунар. журн. экспериментального образования. 2016. № 5-3. С. 272-276.

9. Трубилин А. И., Григоращ О. В. Система оценки знаний и рейтингового тестирования студентов // Политемат. сетевой электрон. науч. журн. Куб. гос. аграр. ун-та. 2016. № 116. С. 1038-1050.

Статья поступила в редакцию 12.04.2019

\section{ИНФОРМАЦИЯ ОБ АВТОРАХ}

\begin{abstract}
Артемьева Евгения Влаgимировна - Россия, 198035, Санкт-Петербург; Госуgарственный университет морского u речного флота имени аgмирала С. О. Макарова; старший препоgаватель кафеgры английского языка навигации u связи; artemyevaev@gumrf.ru.
\end{abstract}

Голубева Варвара Сергеевна - Россия, 198035, Санкт-Петербург; Госуgарственный университет морского и речного флота имени аgмирала С. О. Макарова; старший препоgаватель кафеgры английского языка навигациu u связи; golubevavs@gumrf.ru.

\section{USING TEST-TEACH-TEST APPROACH AT ENGLISH CLASSES}

\author{
E. V. Artemeva, V. S. Golubeva \\ Admiral Makarov State University of Maritime and Inland Shipping, \\ Saint-Petersburg, Russian Federation
}

\begin{abstract}
The article focuses on the benefits of testing as a method in English teaching process and on its types and characteristic features. One of the effective methods of preliminary testing is the Test-Teach-Test method. The Test-Teach-Test method was applied during one semester among the first and second year students of the specialty "Technology of transport processes" at Admiral Makarov State University of Maritime and Inland Shipping. According to the results of the study, it was revealed that the experimental groups in which the Test-Teach-Test method was used demonstrated a better mastery of the material compared to those groups of students who were not taught with the use of this method. It is obvious that its application helps to optimize the process
\end{abstract}


of teaching English, rationally distributing classroom time, applying an individual approach to students, and arranging the classes in a way that maximum attention is paid to the poorly studied material.

Key words: foreign language, testing, teaching process, level of knowledge, preliminary testing, Test-Teach-Test, progress, knowledge monitoring.

For citation: Artemeva E. V., Golubeva V. S. Using Test-Teach-Test approach at English classes. Vestnik of Astrakhan State Technical University. 2019;1(67):57-62. (In Russ.) DOI: $10.24143 / 1812-9498-2019-1-57-62$.

\section{REFERENCES}

1. Corder S. P. Introducing applied linguistics. Harmondsworth; Baltimore, Penguin Books, 1973. 392 p.

2. Ur P. A course in language teaching.Cambridge, Cambridge University Press, 2012. 336 p.

3. Gruzdeva M. L., Kozitsyn A. L. Testirovanie kak forma organizatsii samostoiatel'noî raboty studentov [Testing as a form of organizing students' individual work]. Sovremennye naukoemkie tekhnologii, 2016, no. 7-1, pp. 118-121.

4. Richards J. C. Curriculum development in language teaching. Cambridge, Cambridge University Press, 2001. 336 p.

5. Jin L., Cortazzi M. Re-evaluating traditional approaches to second language teaching and learning. Handbook of research in second language teaching and learning, 2011, vol. 2, pp. 558-575.

6. Larsen-Freeman D. Techniques and principles in language teaching. Oxford, Oxford University Press, 2000. $208 \mathrm{p}$.

7. Hymes D. On communicative competence. Sociolinguistics. Selected Readings. J. B. Pride and J. Holmes (eds.). Harmondsworth, Penguin, 1972. Part 1. Pp. 269-293.

8. Timofeev D. A., Pechnikova A. D., Abyzova N. V. Testirovanie v sisteme metodov kontrolia i otsenki

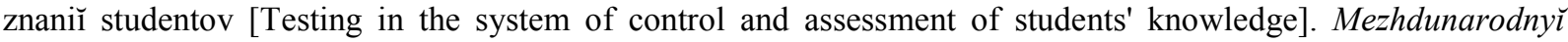
zhurnal èksperimental'nogo obrazovaniia, 2016, no. 5-3, pp. 272-276.

9. Trubilin A. I., Grigorash O. V. Sistema otsenki znaniı̌ i reĭtingovogo testirovaniia studentov [System

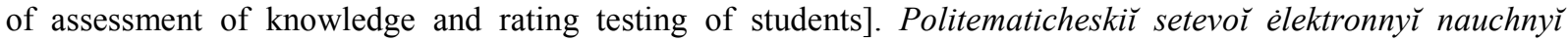
zhurnal Kubanskogo gosudarstvennogo agrarnogo universiteta, 2016, no. 116, pp. 1038-1050.

The article submitted to the editors 12.04.2019

\section{INFORMATION ABOUT THE AUTHORS}

Artemeva Evgeniia Vladimirovna - Russia, 198035, Saint-Petersburg; Admiral Makarov State University of Maritime and Inland Shipping; Senior Lecturer of the Department of English Language, Navigation and Communication; artemyevaev@gumrf.ru.

Golubeva Varvara Sergeevna - Russia, 198035, Saint-Petersburg; Admiral Makarov State University of Maritime and Inland Shipping; Senior Lecturer of the Department of English Language, Navigation and Communication; golubevavs@gumrf.ru. 